\title{
Comparing the effects of livestock and native herbivores on plant production and vegetation composition in the Trans-Himalayas
}

\author{
Sumanta Bagchi ${ }^{1,2,34^{*}}$, Yash V Bhatnagar ${ }^{2}$ and Mark E Ritchie ${ }^{1}$
}

\author{
* Correspondence: sumanta@ \\ conservation.in \\ ${ }^{1}$ Department of Biology, Syracuse \\ University, 107 College Place, \\ Syracuse, NY 13244, USA \\ ${ }^{2}$ Nature Conservation Foundation, \\ 3076/5, 4th Cross, Gokulam Park, \\ Mysore, Karnataka 570002, India \\ Full list of author information is \\ available at the end of the article
}

\begin{abstract}
Grazing can have implications for ecosystem management, biodiversity conservation, human livelihoods and global biogeochemical cycles. Grazers can either depress or promote plant production, with weak or strong effects on vegetation composition. Such variability is a major challenge for sustaining production while avoiding undesirable vegetation shifts. It is also uncertain how knowledge obtained from native herbivores can be used to manage domestic livestock and vice versa. In addition, grazer effects on production and vegetation composition tend to vary along prominent environmental gradients and are also negatively related to each other. Here, we evaluate these patterns for both livestock and native grazers under comparable grazing intensity and evaluate competing hypotheses that can account for the negative co-variation between these two types of grazer effects. A dataset from a four-year herbivore exclusion experiment in the Trans-Himalayan ecosystem in northern India shows the following: (a) grazer effects on plant production and on vegetation composition were indeed negatively correlated, but the relationship depends on the choice of data metrics; (b) incidental autocorrelation due to an underlying soil moisture gradient does not fully explain this pattern; instead, (c) their relationship is explained by variation in local plant species richness. Vegetation responses after excluding livestock and native grazers were qualitatively similar. But, despite comparable grazing intensity, livestock had quantitatively stronger effects on plant species composition. Production in species-rich communities was more grazing-tolerant and showed greater compositional stability. So, understanding the determinants of variation in species richness and how it is, in turn, influenced by grazing can offer a framework to interpret and manage highly variable impacts of herbivores on grazing ecosystems.
\end{abstract}

Keywords: Grazing, Ungulates, Grassland management, Herbivory, Productivity, Species diversity, Stability, Semi-arid rangeland

\section{Background}

Terrestrial grazing ecosystems, featuring both wild and domestic ungulates, represent the most expansive land use, encompassing semi-arid to arid regions of the world (Du Toit et al. 2010). Here, the primary management concern is to sustain animal populations without compromising the ecosystem structure and function for which grazer effects on (1) plant community composition and (2) plant production are most relevant to managers (Levin 1993; Watkinson and Ormerod 2001). Natural ecosystems

\section{Springer}

(c) 2012 Bagchi et al.; licensee Springer. This is an Open Access article distributed under the terms of the Creative Commons Attribution License (http://creativecommons.org/licenses/by/2.0), which permits unrestricted use, distribution, and reproduction in any medium, provided the original work is properly cited. 
with a long history of grazing can be resilient to changes in species composition over decadal timescales but may be more responsive to variation in climate (e.g. East African savannas; Anderson 2008). Human-modified ecosystems on the other hand - where native ungulates have been replaced by domestic livestock (Crosby 1986; Prins 1992) - can experience reduced ecosystem function (Bagchi and Ritchie 2010b) with consequences for biodiversity, human livelihoods and global biogeochemical cycling (FAO 2007, Reid et al. 2010), although under different socio-ecological settings, there is evidence for both competition as well as facilitation between wild and domestic herbivores (e.g. Bagchi et al. 2004; Mishra et al. 2004; Young et al. 2005; Namgail et al. 2008), and recent initiatives have explored greater coexistence under such multiple-use scenarios (e.g. Mishra et al. 2010, Augustine et al. 2011).

These differences between natural and human-modified ecosystems are often attributed to the high stocking densities of livestock, but recent studies have found this view to be overly simplistic (Fuhlendorf and Engle 2004; Bagchi and Ritchie 2010b; Winter et al. 2012). Intensive commercial ranching poses numerous challenges for ecosystem management in all continents (e.g. Fleischner 1994; Cabral et al. 2003; McIntyre et al. 2003; Albon et al. 2007). Even traditional pastoral land use is often thought to be inconsistent with the goals of conservation (Prins 1992), although studies have asserted that all forms of degradation and wildlife declines are not necessarily related to pastoralism per se (e.g. Homewood et al. 2001). Therefore, considerable uncertainties persist over how to utilize information from natural ecosystems to manage human-modified ecosystems and vice versa (Levin 1993; Watkinson and Ormerod 2001). This is further compounded by high variability as the effects of grazing can differ considerably, even idiosyncratically, between ecosystems (Milchunas and Lauenroth 1993; Proulx and Mazumder 1998; Olff and Ritchie 1998; Chase et al. 2000; Vesk and Westoby 2001; Gruner et al. 2008). But, amidst these differences, both within and between ecosystems, an important insight for managers is that grazer effects may vary predictably along prominent natural environmental gradients such as precipitation (Milchunas and Lauenroth 1993; Olff and Ritchie 1998; Anderson et al. 2007; May et al. 2009).

So, is it possible to account for variability by developing site-specific management policies depending on prevailing soil and climatic conditions? Such a scenario would be relatively straightforward, but studies have also found that grazer effects on vegetation composition and on plant production not only vary across ecosystems, but also co-vary with one another. Specifically, grazer effects on plant community composition are inversely related to their corresponding effects on plant production (Milchunas and Lauenroth 1993; Chase et al. 2000). This additional complexity suggests that understanding the mechanisms that establish their inter-dependency may be critical, but these aspects remain inadequately resolved to inform ecosystem management.

Therefore, two important questions then become as follows: (1) Can comparable levels of grazing by native ungulates and livestock have different effects on vegetation composition and production? (2) Why do grazer effects on vegetation composition and on plant production co-vary? Several lines of explanations, or null hypotheses, can be offered to account for the observed negative co-variation between grazer effects (Table 1). One explanation may invoke biogeographical legacies. When data from different ecosystems are summarized in cross-site reviews (Milchunas and Lauenroth 1993; Chase et al. 2000), composite patterns may emerge coincidentally due to differences in latitude, 
Table 1 Alternative explanations for observed negative co-variation between grazer effects on plant communities and plant production

\begin{tabular}{llll}
\hline Scenario & Explanation & Description & Test \\
\hline A & Biogeography & $\begin{array}{l}\text { Merging data across ecosystems can lead to } \\
\text { false patterns }\end{array}$ & $\begin{array}{l}\text { Does the pattern occur within an } \\
\text { ecosystem }\end{array}$ \\
B & $\begin{array}{l}\text { Inconsistent } \\
\text { parameters }\end{array}$ & $\begin{array}{l}\text { Studies reporting effects on plant biomass } \\
\text { and production are pooled together } \\
\text { Studies reporting changes in relative } \\
\text { abundance and species occurrence are } \\
\text { pooled together }\end{array}$ & $\begin{array}{l}\text { Compare patterns of biomass } \\
\text { against those of production } \\
\text { Compare patterns in the Bray-Curtis } \\
\text { index against the Sørensen index }\end{array}$ \\
C & Autocorrelation & $\begin{array}{l}\text { Each response is independently related to a } \\
\text { gradient of precipitation }\end{array}$ & $\begin{array}{l}\text { Assess autocorrelation with soil } \\
\text { moisture }\end{array}$ \\
& Species richness & $\begin{array}{l}\text { Local variation in species richness determines } \\
\text { the strength of each response }\end{array}$ & Evaluate partial correlation \\
\hline
\end{tabular}

Alternative scenarios (A to $D$ ) are listed alongside a description of their underlying arguments and the analytical tests to evaluate them.

altitude, soil fertility and climate. But, if the co-variation is non-trivial, then it should be detected within an ecosystem as well (scenario A, Table 1); such evidence remains fragmentary (Kuijper and Bakker 2005; Anderson et al. 2007; Pajunen et al. 2008). Another explanation may invoke inconsistencies due to the collation of data from widely different methodologies. Indeed, some studies document grazer effects on plant biomass, while others evaluated plant production. Likewise, some studies document change in vegetation composition with relative abundance of plant species, while other studies rely on species occurrence (scenario B, Table 1). One can also implicate statistical artifacts. If each of these two responses to grazing - in plant communities and in plant production - is independently related to another variable, then this could yield an autocorrelation (scenario C, Table 1). Indeed, grazer effects on plant community composition are known to increase along the gradient of precipitation, while the effects on production decline along the same gradient (Chase et al. 2000).

Finally, a non-trivial explanation may posit that these responses may be functionally, if not mechanistically, related to each other, due to an underlying role of species diversity and identity (de Mazancourt and Loreau 2000; Garibaldi et al. 2007). For example, studies often document scenarios where species-rich communities are more resistant to compositional change than species-poor communities (e.g. Frank and McNaughton 1991), and such diversity-stability relationships may even extend to the ecosystem structure and function (Proulx et al. 2010; Haddad et al. 2011; Aragón et al. 2011). So, do the determinants of variation in species diversity across natural gradients influence whether grazing has weak or strong effects on plant communities vis-à-vis plant production? If so, then this provides a conceptual framework for interpreting, and potentially managing, the effects of grazing on the ecosystem structure and function.

Here, we visit a dataset from an herbivore exclusion experiment in the shrub-steppes of the Trans-Himalayan ecosystem of northern India (Bagchi and Ritchie 2010a; Bagchi and Ritchie 2010b) to scrutinize the co-variation between grazer effects - under both native ungulates and livestock at a comparable grazing intensity - on plant communities and on plant production. We confront the alternative scenarios (Table 1) to investigate whether the co-variation between the two responses is (1) detected within an ecosystem; (2) consistent between native and livestock grazers; (3) influenced by choice of data metrics, viz. biomass or production, and relative abundance or species occurrence; (4) 
merely a statistical autocorrelation due to an underlying soil moisture gradient; and (5) explained by variation in plant species richness.

\section{Methods}

\section{Study area and experimental design}

Agro-pastoral settlements across a mountainous landscape in the Spiti region of northern India (4,300- to 4,500-m elevation) have established rangelands that are either grazed primarily by domestic livestock (goat, sheep, donkey, horse, cattle and yak-cattle hybrids) or by free-ranging native herbivores (ibex, Capra sibirica; bharal, Pseudois nayaur; yak, Bos grunniens) (Bagchi and Ritchie 2010b). Livestock are herded to these rangelands nearly year round, with three to seven days separating consecutive visits, although visitation declines between January and March due to snow cover, when they are stall-fed. The rangelands are demarcated by natural features - ridges, canyons and streams - rather than by fencing. So, although native herbivores are not physically excluded, they generally avoid areas that are frequently visited by livestock. While the predominantly Buddhist society is not known to actively engage in hunting, retaliatory persecution of carnivores in response to livestock losses - since both native herbivores and livestock are prey for predators such as the snow leopard (Uncia uncia; Bagchi and Mishra 2006) - is a conservation challenge across the greater Trans-Himalayan landscape.

Importantly, grazing intensity, measured using $1-\mathrm{m}^{2}$ cages at monthly intervals during the growth season following the study of McNaughton et al. (1996), was comparable between the rangelands used by livestock and by native herbivores. Between 2005 and 2007 , native herbivores consumed between $45 \%( \pm 8 \% \mathrm{SE})$ and $66 \%( \pm 11 \% \mathrm{SE})$ of plant production, whereas the livestock consumed between $55 \%( \pm 5 \% \mathrm{SE})$ and $64 \%$ $( \pm 9 \% \mathrm{SE})$ of plant production, and these grazing intensities were not statistically distinguishable from one another $\left(F_{1,5}=0.49, P=0.51\right.$; Bagchi and Ritchie 2010b). Historical grazing pressures were also likely to be comparable to the prevailing conditions (Bagchi and Ritchie 2010b). Here, similar to other ecosystems (e.g. Frank and McNaughton 1993), grazers are known to have favourable effects on net aboveground plant production (Bagchi and Ritchie 2010a). Concomitantly, similar to other ecosystems (e.g. Anderson et al. 2007), experimental herbivore exclusion at this site is accompanied by shifts in species composition: an increase in the relative abundance of forbs and grasses and a decline in sedges (Bagchi and Ritchie 2010b).

The Trans-Himalayan climate is cold and arid with temperatures dropping below $-30^{\circ} \mathrm{C}$ between November and March, with a short growth season for plants (May to August). The annual precipitation is 200 to $400 \mathrm{~mm}$, and most of it occurs as snow outside the short growth season. As in other high-altitude ecosystems, plant growth is primarily dependent on soil moisture derived from the early-season snowmelt (April to May) rather than on the late-season monsoon in India (August). Terrain and topography influence snowpack and snowmelt which results in natural variation in soil moisture across the mountainous landscape. Soils are relatively nutrient-poor, and plant production is also low: the average soil $\mathrm{N}$ is $0.14 \%$, and the average net aboveground production (NAP) is $47 \mathrm{~g} \cdot \mathrm{m}^{-2}$ (Bagchi and Ritchie 2010a).

To create this dataset, 24 herbivore exclosures with a 1.5 -m high chain-linked fence, $100 \mathrm{~m}^{2}$ each with adjacent paired control plots, were set up in May to June 2005. Three to four exclosures were constructed in seven different rangelands surrounding the 
village Kibber $\left(32^{\circ} \mathrm{N}, 78^{\circ} \mathrm{E}\right)$ and spread over an area of approximately $150 \mathrm{~km}^{2}$. Three of these rangelands, containing ten paired plots, were grazed primarily by livestock; four rangelands, containing 14 paired plots, were grazed primarily by the native ungulates (Bagchi and Ritchie 2010b). At each location, the paired fenced and grazed plots were $10 \mathrm{~m}$ apart and were matched by vegetation type, terrain and topography. The sampled vegetation at these locations comprised 39 native perennials such as grasses (Elymus nutans, Festuca olgae, Poa alpina), forbs (Lindelofia anchusoides, Eurotia ceratoides), small shrubs (Caragana versicolor) and sedges (Carex melanantha), while trees were absent (Bagchi and Ritchie 2010b). During the growth seasons from 2005 to 2008, data were collected from the paired grazed and fenced plots on species composition, plant biomass, NAP and soil moisture. Here, we analyse trends in these data after four years of herbivore exclusion.

\section{Data collection}

Plant species richness and community composition

In this dataset, plant species composition was estimated using 50 points along a $10-\mathrm{m}$ line intercept located at the centre of each plot during peak standing biomass (early August; Bagchi and Ritchie 2010b). All species were recorded in the sample if there were multiple hits to estimate:

1. Species richness at the beginning of the study and after four years of herbivore exclusion

2. Community evenness at the beginning of the study and after four years of

herbivore exclusion as 1-Simpson's dominance index $D$, with $D=\frac{\sum n_{i}\left(n_{i}-1\right)}{N(N-1)}$, where $n_{i}$ is the abundance of the $i$ th species, and $N$ is the pooled abundance of all species

3. Bray-Curtis dissimilarity index to represent changes in the relative abundance of plant species between the paired grazed and fenced plots after four years, $B=\frac{\sum\left(n_{i k}-n_{j k}\right)}{\sum\left(n_{i k}+n_{j k}\right)}$, where $n_{k j}$ is the abundance of the $i$ th species of the $k$ th sample

4. Sørensen's dissimilarity index to represent changes in species occurrence after four years, $S=\frac{2 c}{a+b}$, where $c$ is the number of shared species, and $a$ and $b$ are the number of species in that pair of samples (Krebs 1989)

\section{Plant production and biomass}

Data on NAP were collected from grazed plots by measuring the average dry weight of the harvested aboveground biomass (sun-drying, and oven-drying at $40{ }^{\circ} \mathrm{C}$ for $48 \mathrm{~h}$ ) of randomly located $1-\mathrm{m}^{2}$ movable exclosures at monthly intervals between May and August. In ungrazed plots, the corresponding data on NAP were from the end of the growth season (Bagchi and Ritchie 2010a). Data on the grazer effect on production were obtained from the log ratio of the grazed NAP relative to the ungrazed NAP (Bagchi and Ritchie 2010a). The grazer effect on plant biomass was calculated as the log ratio of the ungrazed standing biomass relative to the grazed standing biomass at the end of the growth season. 


\section{Soil moisture}

In lieu of a precipitation gradient, we utilized a natural gradient of early-season soil moisture. We estimated the volumetric water content of soil (VWC as percentage) as the average of four to six random locations in a plot using a $20-\mathrm{cm}$ time domain reflectometry

probe (Spectrum Technologies Inc., Plainfield, USA) at monthly intervals, but here, we use the estimates from the early part of the growth season (during May) for analysis.

\section{Data analysis}

We estimated the grazer effects on plant species richness from the difference in the number of species encountered in the paired grazed and ungrazed plots after four years of herbivore exclusion, relative to any pre-existing difference at the beginning of the study, using two-way analysis of variance (ANOVA) with grazing and herbivore type as independent factors. We estimated the grazer effect on community evenness in the same way with a separate two-way ANOVA. We estimated the grazer effects on vegetation composition from species dissimilarity between the paired plots after four years of herbivore exclusion, relative to any initial differences, using paired two-way ANOVA with herbivore type and year as independent factors.

To target the alternative scenarios (Table 1), we used correlation analyses to first evaluate whether there was any negative co-variation between the grazer effects on NAP and on vegetation composition. Next, we assessed whether the choice of data metrics affected the resulting correlations by using all four combinations of data types. Subsequently, we analysed whether any observed negative co-variation was due to the potential autocorrelation with an underlying soil moisture gradient through partial correlation. Likewise, we evaluated whether the negative co-variation was due to the differences in initial species richness between the ungrazed plots at the beginning of the study through partial correlation. Finally, we evaluated the co-variation among these two aspects after accounting for the partial effects of soil moisture and initial species richness. All analyses were performed using R 2.8.1 (R Development Core Team 2008).

\section{Results}

\section{Grazer effect on species richness}

There were no systematic differences in species richness between the paired grazed and ungrazed plots at the beginning of the study in 2005 (Figure 1a), but richness was higher in the areas used by native grazers (Table 2). However, after four years of herbivore exclusion (Figure 1b), species richness was significantly greater in the grazed plots than in the adjacent ungrazed plots, but there was no effect of herbivore type (Table 2).

\section{Grazer effect on community evenness}

There were no systematic differences in plant community evenness (Figure 1c) between the paired grazed and ungrazed plots at the beginning of the study in 2005, but evenness was higher in the areas used by native grazers (Table 2). Similar patterns were observed after four years of herbivore exclusion (Figure 1d); the difference in plant community evenness between the areas used by livestock and native herbivores had decreased (Table 2). Community evenness increased after fencing in the livestock areas, and 


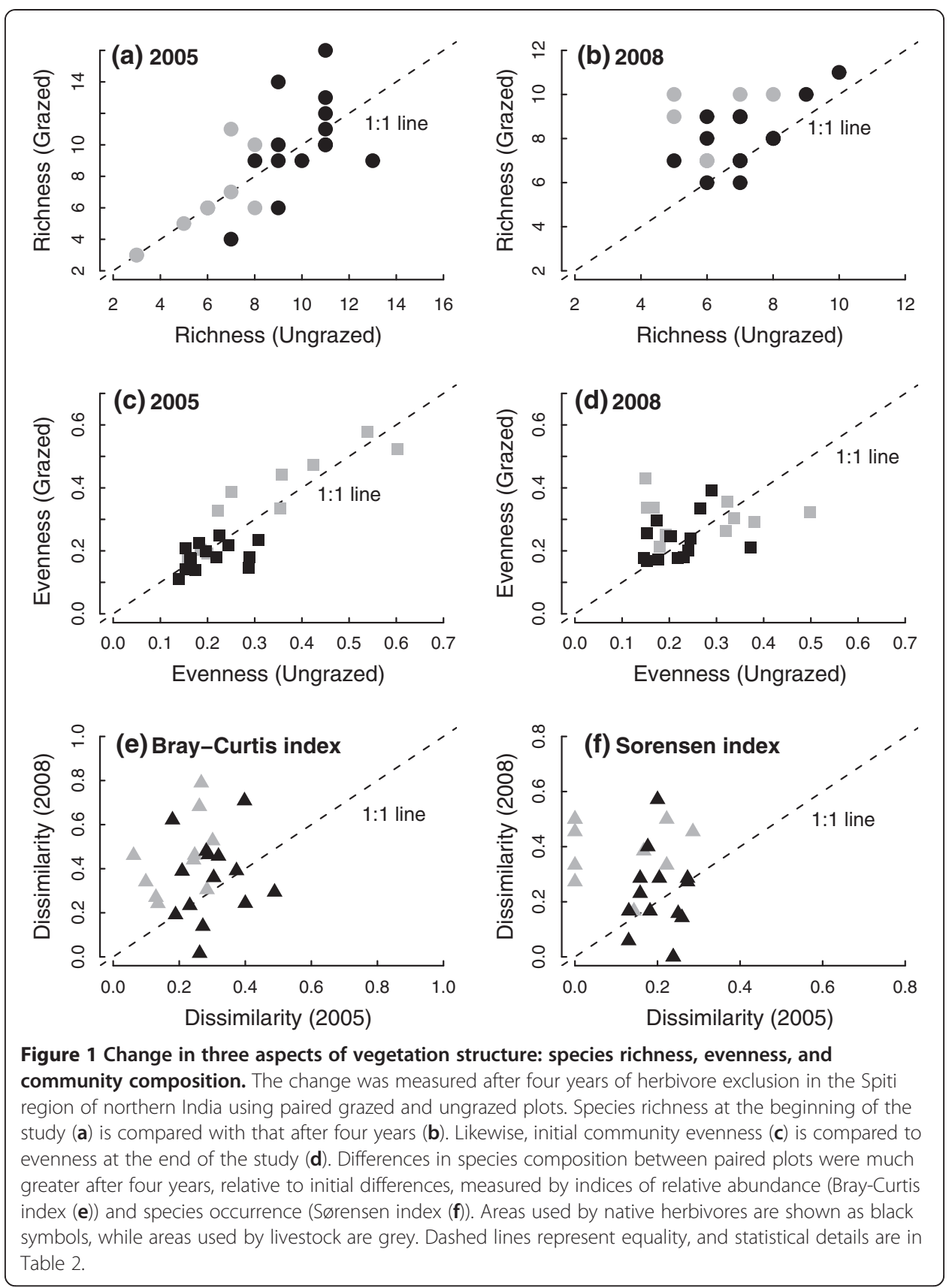

these became comparable to the areas used by native grazers by the end of the study (Figure 1d).

\section{Grazer effect on species composition}

There were modest differences in plant species composition between the paired grazed and ungrazed plots at the beginning of the study, but after four years of herbivore exclusion, compositional differences were significantly greater relative to these initial differences - both in terms of the Bray-Curtis index (Figure 1e) as well as the Sørensen index (Figure 1f). In general, vegetation dissimilarity after four years was nearly twofold 
Table 2 Summary of two-way ANOVAs for grazer effects on species richness and evenness and on species composition for Bray-Curtis index and Sørensen index in Spiti region, northern India

\begin{tabular}{|c|c|c|c|c|c|c|}
\hline Variable & Factor & df & SS & MS & $F$ & $P$ \\
\hline \multirow[t]{4}{*}{ Species Richness (2005) } & Grazing & 1 & 0.75 & 0.75 & 0.13 & 0.71 \\
\hline & Herbivore type & 1 & 184.01 & 184.01 & 33.36 & $<0.001$ \\
\hline & Interaction & 1 & 0.19 & 0.19 & 0.03 & 0.85 \\
\hline & Error & 44 & 242.71 & 5.51 & & \\
\hline \multirow[t]{4}{*}{ Species Richness (2008) } & Grazing & 1 & 17.52 & 17.52 & 10.06 & 0.003 \\
\hline & Herbivore type & 1 & 1.80 & 1.80 & 1.03 & 0.31 \\
\hline & Interaction & 1 & 2.07 & 2.07 & 1.19 & 0.28 \\
\hline & Error & 44 & 76.58 & 1.74 & & \\
\hline \multirow[t]{4}{*}{ Evenness (2005) } & Grazing & 1 & 0.01 & 0.01 & 0.01 & 0.96 \\
\hline & Herbivore type & 1 & 0.26 & 0.26 & 25.52 & $<0.001$ \\
\hline & Interaction & 1 & 0.01 & 0.01 & 0.91 & 0.34 \\
\hline & Error & 44 & 0.46 & 0.01 & & \\
\hline \multirow[t]{4}{*}{ Evenness (2008) } & Grazing & 1 & 0.01 & 0.01 & 1.41 & 0.24 \\
\hline & Herbivore type & 1 & 0.05 & 0.05 & 7.46 & 0.01 \\
\hline & Interaction & 1 & 0.01 & 0.01 & 0.27 & 0.60 \\
\hline & Error & 44 & 0.27 & 0.01 & & \\
\hline \multirow[t]{4}{*}{ Bray-Curtis dissimilarity } & Herbivore type & 1 & 0.01 & 0.01 & 0.66 & 0.42 \\
\hline & Time & 1 & 0.21 & 0.21 & 14.81 & $<0.001$ \\
\hline & Interaction & 1 & 0.17 & 0.17 & 11.97 & $<0.001$ \\
\hline & Error & 44 & 0.62 & 0.01 & & \\
\hline \multirow[t]{4}{*}{ Sørensen dissimilarity } & Herbivore type & 1 & 0.02 & 0.02 & 1.18 & 0.29 \\
\hline & Time & 1 & 0.19 & 0.19 & 14.41 & $<0.001$ \\
\hline & Interaction & 1 & 0.22 & 0.22 & 16.77 & $<0.001$ \\
\hline & Error & 44 & 0.58 & 0.01 & & \\
\hline
\end{tabular}

$\mathrm{df}$, degrees of freedom; SS, sum of squares; MS, mean squares.

compared to the initial differences (Figures 1e,f). Excluding the livestock led to a greater change in species composition than excluding the native grazers (Table 2).

\section{Co-variation between grazer effects}

We detected a significant negative correlation between the grazer effects on NAP and on plant species composition in the study area, but the choice of data metrics influenced the overall pattern (Figure 2). The grazer effect on NAP was negatively correlated with both the Bray-Curtis dissimilarity (Figure 2a) and Sørensen dissimilarity (Figure 2b) indices, and the trend did not differ between herbivore types $\left(F_{1,20}=1.99, P=0.17\right.$ for the Bray-Curtis index; $F_{1,20}=1.38, P=0.25$ for the Sørensen index). But the grazer effect on biomass was not correlated with the indices of species composition change regardless of herbivore type (Figures 2c,d).

\section{Autocorrelation with soil moisture}

Grazer effects on NAP were positively correlated with soil moisture, but the correlation was statistically not significant (Figure 3a) and did not vary between the areas used by 

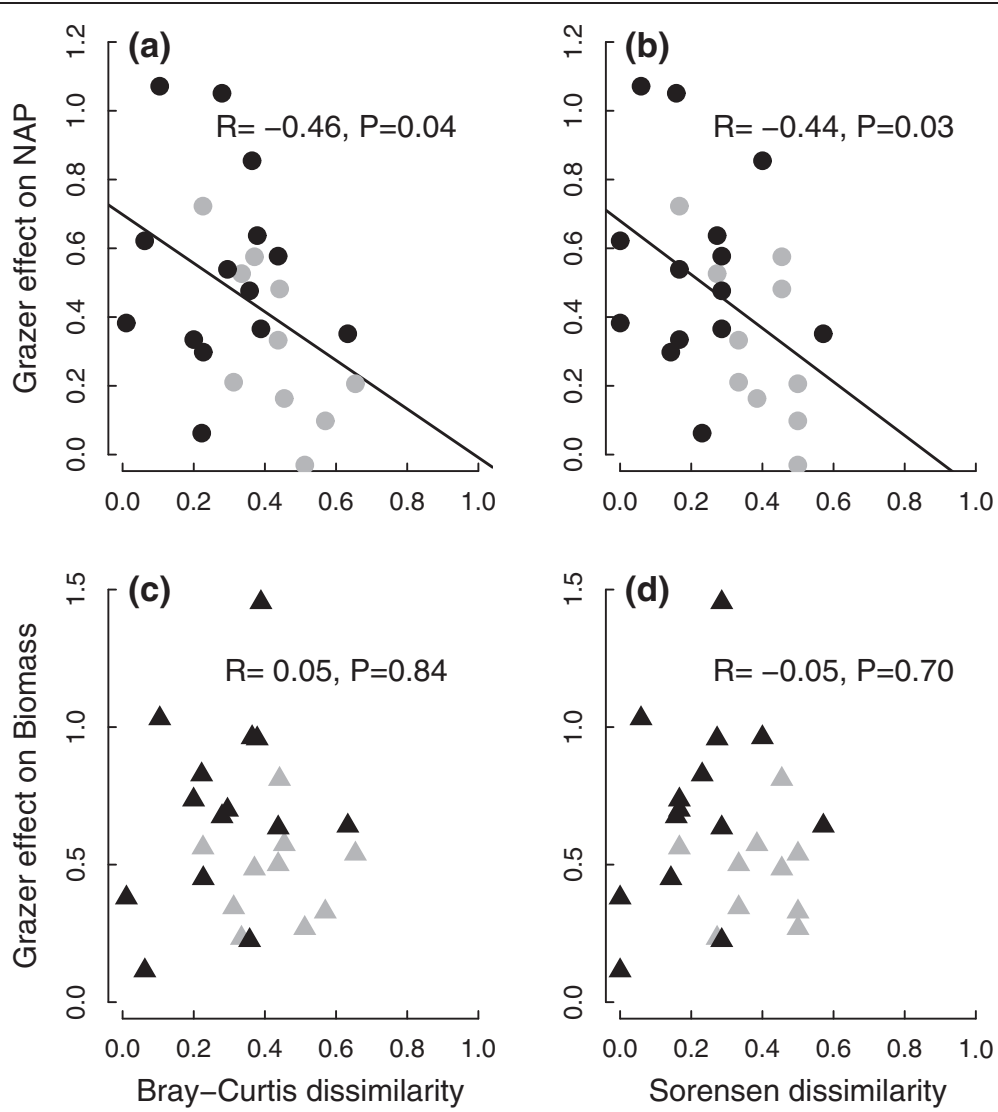

Figure 2 Four ways to express the relationship between grazer effects on plant production or biomass and on species composition, in Spiti region of northern India. Community-level response is represented by species dissimilarity over relative abundance (Bray-Curtis index $(\mathbf{a}, \mathbf{c})$ ) and over species occurrence (Sørensen index $(\mathbf{b}, \mathbf{d})$ ). Areas used by native herbivores are shown as black symbols, while areas used by livestock are grey. Solid lines, when shown, represent the linear relationship between variables.

livestock and native grazers $\left(F_{1,20}=0.11, P=0.73\right)$. Grazer effects on plant biomass, and on species composition, were not related to soil moisture regardless of whether the area was used by native or livestock grazers (Figure 3b,c,d).

\section{Influence of species richness}

The grazer effect on NAP showed a positive correlation with initial species richness (Figure 4a), and this trend did not differ between the areas used by livestock and native grazers $\left(F_{1,20}=1.62, P=0.21\right)$. But the grazer effect on biomass was not significantly related to species richness (Figure $4 \mathrm{~b}$ ). Expectedly, both measures of species composition change were related to initial species richness, and each showed negative correlations (Figures $4 \mathrm{c}, \mathrm{d})$. This trend did not differ between herbivore types $\left(F_{1,20}=1.58\right.$, $P=0.22$ for the Bray-Curtis index; $F_{1,20}=1.02, P=0.32$ for the Sørensen index). A considerable negative partial correlation between the grazer effects on NAP and on species composition persisted even after accounting for the concomitant variation in soil moisture, both as the Bray-Curtis dissimilarity $(R=-0.36, P=0.06)$ and as the Sørensen dissimilarity $(R=-0.38, P=0.06)$. But there was no detectable correlation between the grazer effects on NAP and on species composition after accounting for initial species 


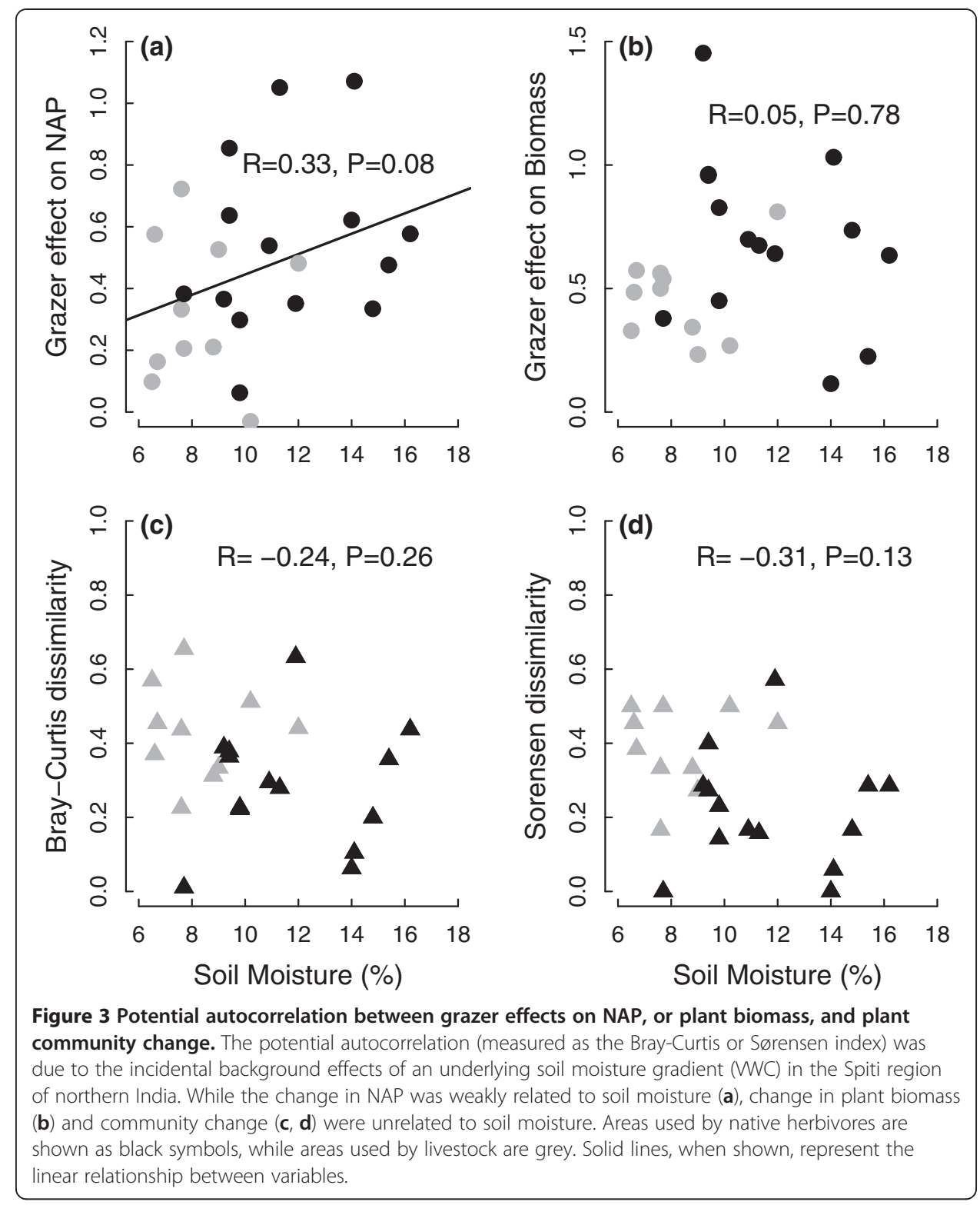

richness, both as the Bray-Curtis dissimilarity $(R=-0.27, P=0.18)$ and as the Sørensen dissimilarity $(R=-0.28, P=0.17)$. Expectedly, once the potential influences of both soil moisture and species richness were removed, there was no partial correlation between the grazer effects on NAP and on species composition change measured by either dissimilarity index (Figures 5a,b).

\section{Discussion}

These data may help understand how herbivores modulate the structure and function of grazing ecosystems, particularly under multiple-use scenarios (Du Toit et al. 2010), as they show the following: (1) a negative relationship between the grazer effects on plant production and on vegetation composition, but this was influenced by the choice of data metrics; (2) the incidental autocorrelation due to the background variation in soil moisture is likely less important than the variation in local plant species richness. 


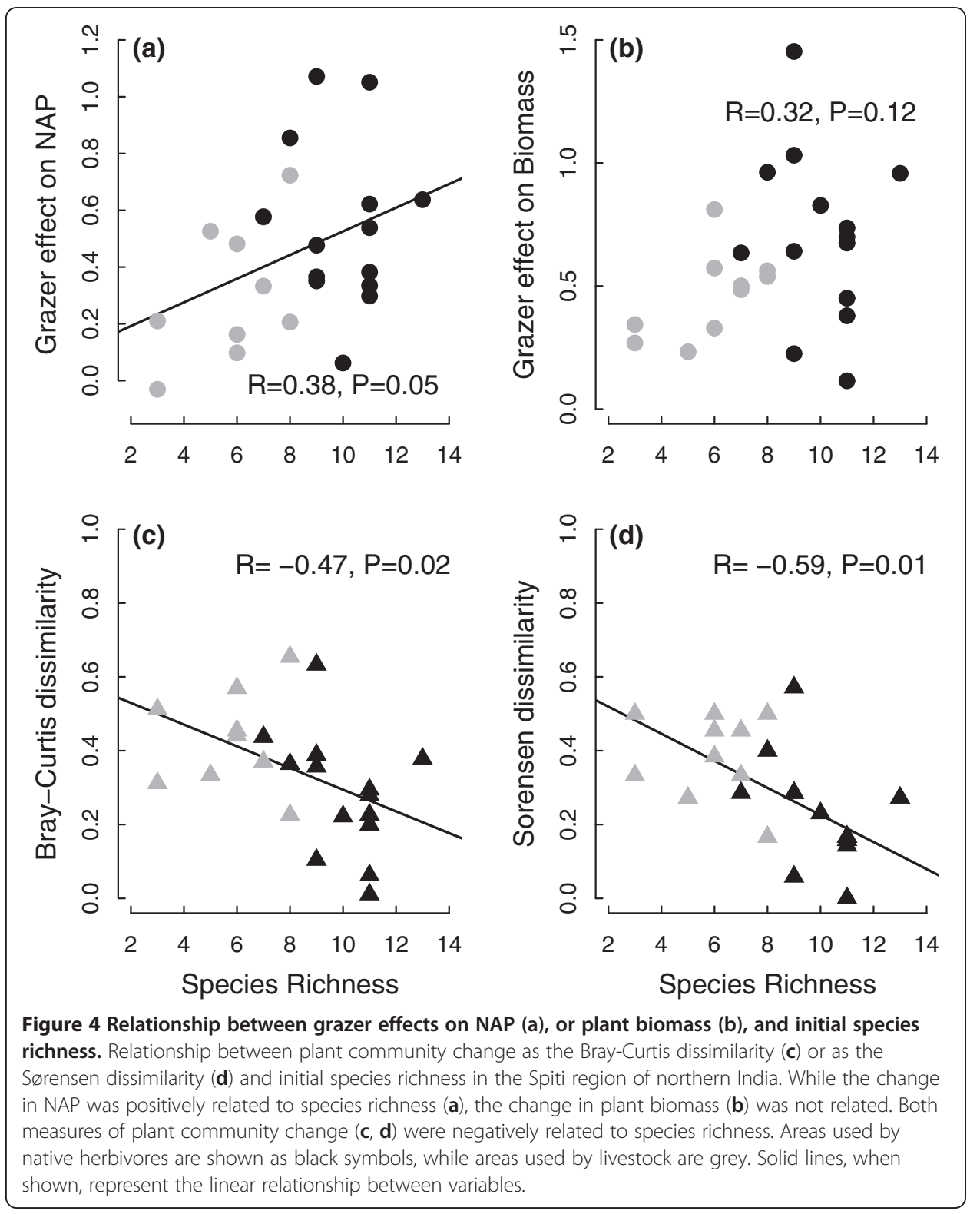

The pattern of co-variation between the grazer effects was qualitatively comparable under both native herbivores and livestock. But, despite similar grazing intensity (Bagchi and Ritchie 2010b), livestock had a stronger effect on plant community composition than native grazers as their exclusion resulted in greater change in plant species composition (Figures 1e,f). These results may have practical implications for the management of natural and human-modified ecosystems.

These data can distinguish between the alternative explanations on why grazer effects on vegetation composition co-vary with their effects on plant production (Table 1). They suggest that the observed negative co-variation may not be a trivial outcome of biogeographical differences (scenario A, Table 1). They also suggest that the choice of data metrics is an important consideration (scenario B, Table 1). While autocorrelation with a moisture gradient, or broadly with precipitation, can be partially responsible, this alone does not dismiss the pattern as a mere statistical artifact (scenario C, Table 1). 

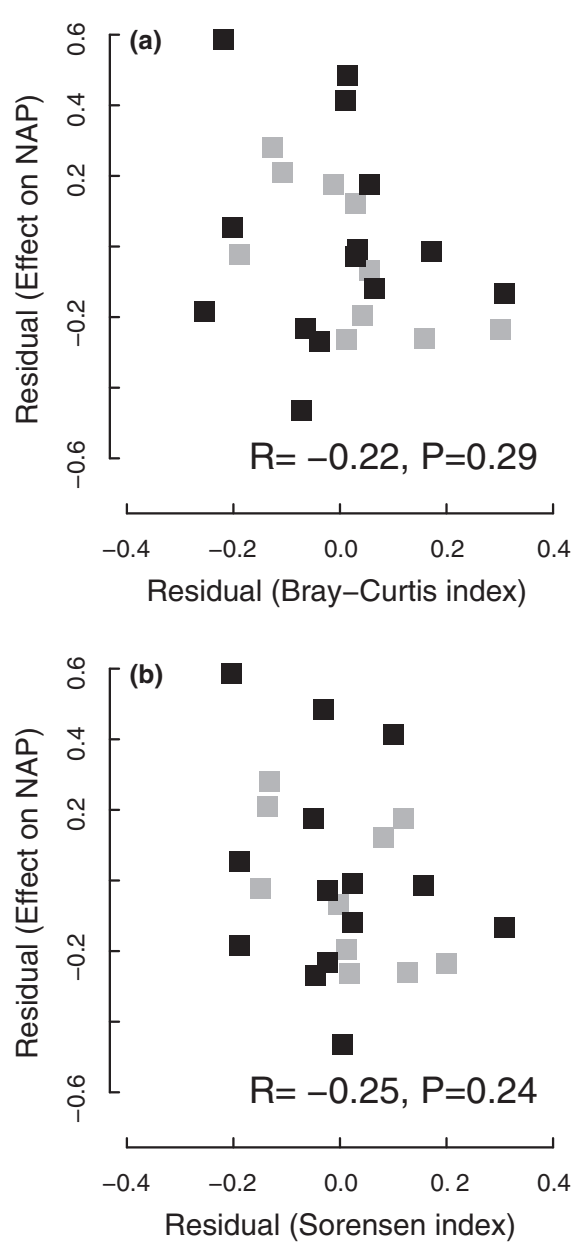

Figure 5 Partial correlation between grazer effects on NAP and on plant community composition. The partial correlation is represented as the Bray-Curtis dissimilarity (a) and as the Sørensen dissimilarity (b) after removing potential influences of soil moisture and species richness in the Spiti region of northern India. Patterns indicate a lack of residual co-variation.

Instead, our results are consistent with the hypothesis that determinants of species richness may influence whether grazers have weak or strong impacts on vegetation composition and, simultaneously, on production (scenario D, Table 1).

For a low-productivity ecosystem with relatively nutrient-poor soils in this case (Milchunas and Lauenroth 1993; Olff and Ritchie 1998; Chase et al. 2000), grazers, expectedly, had favourable impacts on local plant species richness, and herbivore exclusion also led to strong responses in vegetation composition (Figure 1). Consistent with other studies (Frank and McNaughton 1991), species-poor communities underwent greater compositional change compared to species-rich communities (Figures 4c,d). This likely reflects the combined effects of herbivores on dominance hierarchies and on colonization-extinction processes (Olff and Ritchie 1998) and is consistent with the general premise that species richness influences compositional stability (Frank and McNaughton 1991).

Also important is the positive relationship between the grazer effects on production and initial species richness (Figure 4a). Under what circumstances should species-rich 
communities show a stronger response to grazing than species-poor communities? Herbivores' effects on species composition are mediated by selective foraging (Augustine and McNaughton 1998; Ritchie and Olff 1999), inter-specific differences in diet selectivity (Bagchi and Ritchie 2010b) and plant regrowth after defoliation (Bagchi and Ritchie 2011). Non-selective foraging can effectively promote dominance by one or a few grazingtolerant plants and thereby establish species-poor conditions. Production in these communities, due to the predominance of tolerance traits (de Mazancourt and Loreau 2000), is likely to show a large response to grazing (Figure 4a), and it is also likely to undergo large compositional shifts after herbivore exclusion (Figure 4c,d).

\section{Relevance to grazing management}

The data align favourably with the previous studies (Olff and Ritchie 1998) that grazer effects may vary predictably with natural gradients, and their co-variation may be functionally related to the determinants of local species richness (de Mazancourt and Loreau 2000), although these data do not clarify the underlying mechanisms of such functional linkages. Therefore, rather than idiosyncratic variability, the highly variable grazer impacts in different ecosystems may, in fact, be interpretable in a manner that can inform managers (Levin 1993; Watkinson and Ormerod 2001). These can be viewed in terms of qualitative similarities, and quantitative differences, between the effects of livestock and native grazers.

\section{Qualitative similarities between livestock and native grazers}

The effect of both livestock and native grazers on plant production was negatively correlated to their impact on species composition, and this was explained by the local variation in plant species richness. This indicates that, when grazing intensities are carefully managed, information from natural ecosystems may be broadly relevant to human-modified ecosystems and vice versa (Levin 1993; Watkinson and Ormerod 2001). In agreement with the well-documented patterns of plant production in experimental (Tilman et al. 1997) as well as natural settings (Bai et al. 2007), species-rich communities were more tolerant of grazing (Figure 4). Furthermore, as seen in other ecosystems (Frank and McNaughton 1991) species-rich communities also showed greater compositional stability under grazing (Figure 4). So, fostering local species diversity could facilitate the overarching management goal of maintaining plant production while avoiding large vegetation shifts. In addition to mechanistic and niche-based factors that relate to edaphic heterogeneity, grazing can also be an important determinant of species richness. Thus, understanding the determinants of species diversity not only is an interesting ecological question (Ricklefs and Schluter 1993; Rosenzweig 1995), but can also have practical relevance for management. Beyond grazing tolerance and compositional stability, species diversity is also positively associated with valuable ecosystem services in the TransHimalayas (Bagchi and Ritchie 2010b) and in semi-arid ecosystems globally (Maestre et al. 2012).

\section{Quantitative differences between livestock and native grazers}

The areas used by livestock had lower species richness than the areas used by native grazers at the beginning of the study and could represent the effects of land use change (Bagchi and Ritchie 2010b). But four years of herbivore exclusion led to strong vegetation recovery such that the plant communities released from livestock grazing became 
comparable with the areas used by native grazers (Figure 1). This indicates that livestock may promote dominance by a few grazing-tolerant plants and effectively lower species richness, and community evenness, relative to the effect of native grazers. This effect can be enhanced by the general lack of diet differentiation between the different types of livestock as previously indicated by studies on their diet selectivity (Bagchi and Ritchie 2010b). The results also indicate that managing the livestock's effect on local species richness may be a key management concern, particularly to prevent livestock from reducing plant diversity. Towards this end, several management frameworks have been developed to reduce the negative impacts of livestock on plant diversity, and these have been studied in a variety of environmental settings (e.g. McIntyre et al. 2003; Fuhlendorf and Engle 2004; Albon et al. 2007). Since any effective reduction in species diversity under livestock would amount to a declining ecosystem function compared to native grazers (Bai et al. 2007; Bagchi and Ritchie 2010b), it can be addressed by sitespecific restoration targets (Martin and Wilsey 2006). In summary, an understanding of the determinants of variation in species diversity, and whether it is promoted or depleted by grazers, can lead to a conceptual framework for managing the highly variable effects of grazing on natural and human-modified ecosystems.

Competing interests

The authors declare that they have no competing interests.

\section{Authors' contributions}

SB conducted the fieldwork and wrote the draft manuscript. YVB and MER helped with the study design, fund raising, laboratory methods, data analysis and interpretation, and writing of the manuscript. All authors read and approved the final manuscript.

\section{Acknowledgements}

This work was funded by the US National Science Foundation (DDIG DEB-0608287 to SB) Wildlife Conservation Society and Rufford Maurice Laing Foundation. We thank the Himachal Pradesh Department of Forest Farming and Conservation for their support. Fieldwork was carried out with generous assistance from Dorje 'Sheroo' Chhewang, Tanzin 'Mirinda' Chhewang, Tandup 'Sushil' Dorje, Dorje Chhering, Tanzin Thinle, Swapna N. Reddy and several others from the village Kibber. We benefited from the ideas contributed by M. T. Anderson, D. D. Briske, D. A. Frank, J. D. Fridley, J. B. Grace, S. J. McNaughton, C. Mishra, G. B. Schaller, K. S. G. Sundar, T. Namgail, N. J. Singh, W. T. Starmer and M. A. Thorne-Green.

\section{Author details}

${ }^{1}$ Department of Biology, Syracuse University, 107 College Place, Syracuse, NY 13244, USA. ${ }^{2}$ Nature Conservation Foundation, 3076/5, 4th Cross, Gokulam Park, Mysore, Karnataka 570002, India. ${ }^{3}$ Department of Ecosystem Science and Management, Texas A\&M University, College Station, TX 77843, USA. ${ }^{4}$ Current address: National Institute of Science Education and Research, Bhubaneswar 751005, India.

Received: 8 May 2012 Accepted: 30 August 2012

Published: 28 September 2012

\section{References}

Albon, S.D., M.J. Brewer, S. O'Brien, A.J. Nolan, and D. Cope. 2007. Quantifying the grazing impacts associated with different herbivores on rangelands. Journal of Applied Ecology 44: 1176-1187.

Anderson, T.M. 2008. Plant compositional change over time increases with rainfall in the Serengeti grasslands. Oikos 117: $675-682$

Anderson, T.M., M.E. Ritchie, and S.J. McNaughton. 2007. Rainfall and soils modify plant community response to grazing in Serengeti National Park. Ecology 88: 1191-1201.

Aragón, R., M. Oesterheld, G. Irisarri, and M. Texeira. 2011. Stability of ecosystem functioning and diversity of grasslands at the landscape scale. Landscape Ecology 26: 1011-1022.

Augustine, D.J., and S.J. McNaughton. 1998. Ungulate effects on functional species composition of plant communities: herbivore selectivity and plant tolerance. Journal of Wildlife Management 62: 1164-1182.

Augustine, D.J., K.E. Veblen, J.R. Goheen, C. Riginos, and T.P. Young. 2011. Pathways for positive cattle-wildlife interactions in semi-arid rangelands. Smithsonian Contributions to Zoology 632: 55-71.

Bagchi, S., and C. Mishra. 2006. Living with large carnivores: predation on livestock by the snow leopard (Uncia uncia). Journal of Zoology 268: 217-224.

Bagchi, S., and M.E. Ritchie. 2010a. Herbivore effects on above- and belowground plant production and soil nitrogen availability in the Trans-Himalayas. Oecologia 164: 1075-1082. 
Bagchi, S., and M.E. Ritchie. 2010b. Introduced grazers can restrict potential soil carbon sequestration through impacts on plant community composition. Ecology Letters 13: 959-968.

Bagchi, S., and M.E. Ritchie. 2011. Herbivory and plant tolerance: experimental tests of alternative hypotheses involving non-substitutable resources. Oikos 120: 119-127.

Bagchi, S., C. Mishra, and Y.V. Bhatnagar. 2004. Conflicts between traditional pastoralism and conservation of Himalayan ibex (Capra sibirica) in the Trans-Himalayan mountains. Animal Conservation 7: 121-128.

Bai, Y., J. Wu, Q. Pan, J. Huang, Q. Wang, F. Li, A. Buyantuyev, and X. Han. 2007. Positive linear relationship between productivity and diversity: evidence from the Eurasian steppe. Journal of Applied Ecology 44: 1023-1034.

Cabral, A.C., J.M. de Miguel, A.J. Resica, M.F. Schmitz, and F.D. Pineda. 2003. Shrub encroachment in Argentinean savannas. Journal of Vegetation Science 14: 145-152.

Chase, J.M., M.A. Leibold, A.L. Downing, and J.B. Shurin. 2000. The effects of productivity, herbivory and plant species turnover in grassland food webs. Ecology 81: 2485-2497.

Crosby, A.W. 1986. Ecological imperialism: the biological expansion of Europe 900-1900. Cambridge: Cambridge University Press.

de Mazancourt, C., and M. Loreau. 2000. Effect of herbivory and plant species replacement on primary production. American Naturalist 155: 735-754.

Du Toit, J.T., R. Kock, and J.C. Deutsch. 2010. Wild rangelands: conserving wildlife while maintaining livestock in semi-arid ecosystems. Chichester: Wiley.

FAO. 2007. Livestock's long shadow. Rome: Food and Agriculture Organization of the United Nations.

Fleischner, T.L. 1994. Ecological costs of livestock grazing in western North America. Conservation Biology 8: 629-644.

Frank, D.A., and S.J. McNaughton. 1991. Stability increases with diversity in plant communities: empirical evidence from the 1988 Yellowstone drought. Oikos 62: 360-362.

Frank, D.A., and S.J. McNaughton. 1993. Evidence for the promotion of aboveground grassland production by native large herbivores in Yellowstone National Park. Oecologia 96: 157-161.

Fuhlendorf, S.D., and D.M. Engle. 2004. Application of the fire-grazing interaction to restore a shifting mosaic on tallgrass prairie. Journal of Applied Ecology 41: 604-614.

Garibaldi, L.A., M. Semmartin, and E.J. Chaneton. 2007. Grazing-induced changes in plant composition affect litter quality and nutrient cycling in flooding Pampa grasslands. Oecologia 151: 650-662.

Gruner, D.S., J.E. Smith, E.W. Seabloom, S.A. Sandin, J.T. Ngai, H. Hillebrand, W.S. Harpole, J.J. Elser, E.E. Cleland, and M.E.S. Bracken. 2008. A cross-system synthesis of consumer and nutrient resource control on producer biomass. Ecology Letters 11: 740-755.

Haddad, N.M., G.M. Crutsinger, K. Gross, J. Haarstad, and D. Tilman. 2011. Plant diversity and the stability of foodwebs. Ecology Letters 14: 42-46.

Homewood, K., E.F. Lambin, E. Coast, A. Kariuki, I. Kikula, J. Kivelia, M. Said, S. Serneels, and M. Thompson. 2001. Longterm changes in Serengeti-Mara wildebeest and land cover: pastoralism, population, or policies? Proceedings of the National Academy of Sciences 98: 12544-12549.

Krebs, C.J. 1989. Ecological methodology. New York: Harper Collins.

Kuijper, D.P.J., and J.P. Bakker. 2005. Top-down control of small herbivores on salt marsh vegetation along a productivity gradient. Ecology 86: 914-923.

Levin, S.A. 1993. Forum: grazing theory and rangeland management. Ecological Applications 3: 1.

Maestre, F.T., J.L. Quero, N.J. Gotelli, A. Escudro, et al. 2012. Plant species richness and ecosystem multifunctionality in global drylands. Science 335: 214-218.

Martin, L.M., and B.J. Wilsey. 2006. Assessing grassland restoration success: relative roles of seed additions and native ungulate activities. Journal of Applied Ecology 43: 1098-1109.

May, F., V. Grimm, and F. Jeltsch. 2009. Reversed effects of grazing on plant diversity: the role of below-ground competition and size symmetry. Oikos 118: 1830-1843.

McIntyre, S., K.M. Heard, and T.G. Martin. 2003. The relative importance of cattle grazing in subtropical grasslands: does it reduce or enhance plant diversity? Journal of Applied Ecology 40: 445-457.

McNaughton, S.J., D.G. Milchunas, and D.A. Frank. 1996. How can net primary productivity be measured in grazing ecosystems? Ecology 77: 974-977.

Milchunas, D.G., and W.K. Lauenroth. 1993. Quantitative effects of grazing on vegetation and soils over a global range of environments. Ecological Monographs 63: 327-366.

Mishra, C., S.E. van Wieren, P. Ketner, I.M.A. Heitkonig, and H.H.T. Prins. 2004. Competition between livestock and bharal Pseudois nayaur in the Indian Trans-Himalaya. Journal of Applied Ecology 41: 344-354.

Mishra, C., S. Bagchi, T. Namgail, and Y.V. Bhatnagar. 2010. Multiple use of Trans-Himalayan rangelands: reconciling human livelihoods with wildlife conservation. In Wild rangelands: conserving wildlife while maintaining livestock in semi-arid ecosystems, ed. J.T. Du Toit, R. Kock, and J. Deutsch, 291-311. London: Wiley.

Namgail, T., S. Bagchi, C. Mishra, and Y.V. Bhatnagar. 2008. Distributional correlates of the Tibetan gazelle in northern India: towards a recovery programme. Oryx 42: 107-112.

Olff, H., and M.E. Ritchie. 1998. Effects of herbivores on grassland plant diversity. Trends in Ecology \& Evolution 13: 261-265.

Pajunen, A., R. Virtanen, and H. Roininen. 2008. The effects of reindeer grazing on the composition and species richness of vegetation in forest-tundra ecotone. Polar Biology 31: 1233-1244.

Prins, H.H.T. 1992. The pastoral road to extinction: competition between wildlife and traditional pastoralism in East Africa. Environmental Conservation 19: 117-123.

Proulx, M., and A. Mazumder. 1998. Reversal of grazing impact on plant species richness in nutrient-poor vs. nutrientrich ecosystems. Ecology 79: 2581-2592.

Proulx, R., C. Wirth, W. Voigt, A. Weigelt, C. Roscher, S. Attinger, J. Baade, R.L. Barnard, N. Buchmann, and F. Buscot. 2010. Diversity promotes temporal stability across levels of ecosystem organization in experimental grasslands. PLoS One 5: e13382.

R Development Core Team. 2008. R: a language and environment for statistical computing. Vienna: R Foundation for Statistical Computing. 
Reid, R.S., C. Bedelian, M.Y. Said, R.L. Kruska, R.M. Mauricio, V. Castel, J. Olson, and P.K. Thornton. 2010. Global livestock impacts on biodiversity. In Livestock in a changing landscape, volume 1: drivers, consequences, and responses, ed. $\mathrm{H}$. Steinfeld, H.A. Mooney, F. Schneider, and L.E. Neville, 111-138. Washington DC: Island Press.

Ricklefs, R.E., and D. Schluter. 1993. Species diversity in ecological communities: historical and geographical perspectives. Chicago: University of Chicago Press.

Ritchie, M.E., and H. Olff. 1999. Herbivore diversity and plant dynamics: additive and compensatory effects. In Herbivores: between plants and predators, ed. H. Olff, V.K. Brown, and R.H. Drent, 175-204. Oxford: Blackwell Science.

Rosenzweig, M.L. 1995. Species diversity in space and time. Cambridge: Cambridge University Press.

Tilman, D., J.M.H. Knopps, D. Wedin, P.B. Reich, M.E. Ritchie, and E.H. Siemann. 1997. The influence of functional diversity and composition on ecosystem processes. Science 277: 1300-1302.

Vesk, P.A., and M. Westoby. 2001. Predicting plant species' responses to grazing. Journal of Applied Ecology 38: 897-909.

Watkinson, A.R., and S.J. Ormerod. 2001. Grasslands, grazing and biodiversity: editors' introduction. Journal of Applied Ecology 38: 233-237.

Winter, S.L., S.D. Fuhlendorf, C.L. Goad, C.A. Davis, K.R. Hickman, and D.M. Leslie. 2012. Restoration of the fire-grazing interaction in Aremisis filifolia shrubland. Journal of Applied Ecology 49: 242-250.

Young, T.P., T.M. Palmer, and M.E. Gadd. 2005. Competition and compensation among cattle, zebras, and elephants in a semi-arid savanna in Laikipia, Kenya. Biological Conservation 122: 351-359.

doi:10.1186/2041-7136-2-21

Cite this article as: Bagchi et al: Comparing the effects of livestock and native herbivores on plant production and vegetation composition in the Trans-Himalayas. Pastoralism: Research, Policy and Practice 2012 2:21.

Submit your manuscript to a SpringerOpen ${ }^{\circ}$ journal and benefit from:

- Convenient online submission

- Rigorous peer review

- Immediate publication on acceptance

- Open access: articles freely available online

- High visibility within the field

- Retaining the copyright to your article

Submit your next manuscript at $\boldsymbol{\sim}$ springeropen.com 